Article

\title{
Development of a Polyacrylate/Silica Nanoparticle Hybrid Emulsion for Delaying Nutrient Release in Coated Controlled-Release Urea
}

\author{
Yazhen Shen ${ }^{1}$, Jianmin Zhou ${ }^{1}$ and Changwen Du ${ }^{1,2, *(D)}$ \\ 1 State Key Laboratory of Soil and Sustainable Agriculture, Institute of Soil Science, Chinese Academy of \\ Sciences, Nanjing 210008, China; yzshen@issas.ac.cn (Y.S.); jmzhou@issas.ac.cn (J.Z.) \\ 2 College of Advanced Agricultural Sciences, University of Chinese Academy of Sciences, Beijing 100049, \\ China \\ * Correspondence: chwdu@issas.ac.cn; Tel.: +86-25-8688-1565
}

Received: 7 December 2018; Accepted: 28 January 2019; Published: 31 January 2019

\begin{abstract}
Polyacrylate/silica hybrid emulsions were prepared by blending aqueous silica nanoparticles with polyacrylate emulsion, which were used for coating urea granules. After incorporating $1.0 \mathrm{wt} . \%$ silica nanoparticles into polyacrylate emulsion, preliminary solubility of CRU was decreased from $38.3 \%$ to $2.2 \%$, and the release duration was extended from 8 to 27 days. The hybrid coating remarkably delayed the release of urea via improving wear-resistance due to the enhanced hardness, reducing water vapor permeability because of the tortuous diffusion pathway, and less breakage of CRU granules resulted from higher glass transition temperature. Meanwhile, the processibility was improved, which prevented particle agglomeration during coating. Therefore, aqueous silica nanoparticles have potential application in polymer emulsion coated controlled-release fertilizers.
\end{abstract}

Keywords: controlled-release urea; polymer emulsion coating; silica

\section{Introduction}

Nitrogen is an essential element for maintaining crop growth and plays an irreplaceable role in food safety. Urea is the most widely used nitrogen fertilizer globally [1]. However, urea is vulnerable to loss from runoff, leaching, and volatilization during agricultural production [2,3], which leads to significant economic losses and environmental consequences. Controlled-release urea (CRU) could increase nutrient utilization efficiency because availability would coincide with the crop's requirements [4,5]. Moreover, it reduces the cost of fertilization because one-off application of CRU can meet the crop's demand during the entire growth period [6]. With growing interest in environmental protection, more attention has been paid to polymer emulsion coated urea. Polyacrylate emulsion has appropriate viscosity, good film-forming properties, and low price [7,8]. It affects neither the structure of soil nor the activities of soil microorganisms [9]. Therefore, it is an attractive candidate for coating urea. However, polyacrylate emulsion coated urea releases excessive urea during the first several days. It can easily burn seedlings when coated and conventional urea is commingled in a single application [6]. Besides, it also exhibits poor processability and low strength [10]. In our previous studies, $\mathrm{Fe}^{\mathrm{III}}$-tannic acid complexes-modified polyacrylate emulsion exhibited a satisfactory improvement in controlled-release performance $[10,11]$. However, these measures have no striking effect on improving the processability and strength of the coating. Moreover, graphene oxide was also used to modify polymer emulsions, but no significant effect on controlled release performance was achieved [12,13]. 
Polymer/silica hybrids have received a lot of attention recently because of remarkable improvements in polymer properties, such as superior mechanical strength and chemical resistance [14-21]. Furthermore, the essentially impermeable silica nanoparticles act as obstacles to the water vapor and nutrients, forcing them to follow longer and complicated routes to diffuse through the hybrid films [22]. Therefore, the presence of silica nanoparticles is expected to greatly improve the strength of the coating and reduce the permeability through the hybrid coating. Li et al. (2016) prepared coated urea by modifying polyurethane with mesoporous silica and nano-silica. Mesoporous silica was found highly effective in improving the controlled release performance by forming the interpenetrating networks between polyurethane and well-dispersed mesoporous silica, while nano-silica had almost no effect due to its poor dispersion [23].

Formerly, most silica nanoparticles were prepared with the tetraethyl orthosilicate (TEOS) by sol-gel methods. Organic solvents are needed to dissolve TEOS during the polymerization process, which is not environmentally friendly [24]. Recently, with the development of a novel production method of silica nanoparticles, large-scale preparation of aqueous silica nanoparticles with a high efficiency and a relatively low cost was achieved. Aqueous silica nanoparticles were added to the polyacrylate emulsion, and they were expected to uniformly distribute the emulsion so that the water vapor permeability of the hybrid coating could be reduced and the processability and mechanical strength could be enhanced.

Herein, the different contents of aqueous silica nanoparticles were introduced into polyacrylate emulsion by simple blending, and they were subsequently sprayed onto urea particles to prepare the coated CRU. The influence of aqueous silica nanoparticles on the properties of the hybrid films and the resultant nutrient release profiles of coated CRU were investigated. This method was eco-friendly, facile, and easily scalable.

\section{Materials and Methods}

Silica nanoparticles (approximate primary particle size of $30 \mathrm{~nm}$ and specific surface area of $600 \mathrm{~m}^{2} / \mathrm{g}$ ) were obtained from Beijing DK nano technology Co. Ltd., Beijing, China. Pre-dispersed systems of $30 \%(w / w)$ silica nanoparticles were used to prepare the hybrid emulsions. Methyl methacrylate (MMA, AR), n-butyl acrylate (BA, CP), and methacrylic acid (MAA, CP) were purchased from Nanjing Chemical Regent Co., Ltd., Nanjing, China. Sodium dodecylbenzenesulfonate (SDBS, AR) was obtained from Chengdu Kelong Chemical Reagent Co., Ltd., Chengdu, China. Nonyl phenyl polyoxyethylene ether-10 (OP-10, CP) was obtained from Hebei Xingtai Kewang Auxiliary Agent Co., Ltd., Xingtai, China. Urea granules (46.6 wt.\% of nitrogen and $2.00-4.75 \mathrm{~mm}$ in diameter) were purchased by Shandong Luxi Fertilizer Co., Ltd., Liaocheng, China. Deionized water was used throughout the experiment.

The polyacrylate emulsion was prepared by a semi-continuous conventional emulsion polymerization procedure [8]. The polyacrylate had a mass ratio of BA:MMA:MAA $=55: 45: 2.5$ and the solid content of $40 \mathrm{wt} . \%$. The emulsion microspheres that were used as the coating material had an average diameter of $156 \mathrm{~nm}$. Polyacrylate/silica hybrid emulsions were prepared by mixing at room temperature. Firstly, a certain amount of aqueous silica nanoparticles was dispersed in $100 \mathrm{~mL}$ of deionized water under mechanical stirring for $10 \mathrm{~min}$ and under ultrasonic dispersion for another $10 \mathrm{~min}$. The amounts of silica nanoparticles were set as $0.5 \mathrm{wt} . \%, 1.0 \mathrm{wt} . \%, 1.5 \mathrm{wt} . \%$, and $2.0 \mathrm{wt} . \%$, and the resultant films were designated as Silica $0.5 \%$, Silica $1.0 \%$, Silica $1.5 \%$, and Silica $2.0 \%$, respectively. Then, the silica dispersion was blended with $100 \mathrm{~g}$ polyacrylate emulsion and they were stirred for $10 \mathrm{~min}$ at room temperature to obtain the polyacrylate/silica hybrid emulsion. Finally, the hybrid emulsions were used to prepare coated CRU and hybrid films. Pure polyacrylate emulsion without adding silica was prepared in a similar manner to form the reference coating emulsion, Silica $0 \%$. The films were obtained by casting the prepared emulsion onto a $9 \mathrm{~cm}^{2}$ leveled plastic cap and drying in an oven at $60^{\circ} \mathrm{C}$ to a constant weight. The dry films were removed from the plastic caps for further characterization. 
The spectra of pure polyacrylate and hybrid films were determined by An FTIR spectrometer (Nicolet 6700, Thermo Scientific, Waltham, MA, USA) equipped with a photoacoustic accessory (model 300, MTEC, Oakland, CA, USA). The scans were conducted in the wavenumber range of $1000-3250 \mathrm{~cm}^{-1}$. The resolution and mirror velocity were set to $4 \mathrm{~cm}^{-1}$ and $0.63 \mathrm{~cm} / \mathrm{s}$, respectively. Thirty-two successive scans were recorded.

The water uptake of isolate films was determined by the following procedure [13]: the weighed film $\left(W_{\mathrm{f} 1}\right)$ was immersed in deionized water at $25^{\circ} \mathrm{C}$ for 15 days. Soaked films were wiped with a piece of filter paper to determine the weight $\left(W_{\mathrm{f} 2}\right)$ every three days. Water uptake was defined as $\left(W_{\mathrm{f} 2}-W_{\mathrm{f} 1}\right) \times 100 / \mathrm{W}_{\mathrm{f} 1}$ with three replicates.

Water vapor permeability of films with a thickness of $0.85 \mathrm{~mm}$ was measured according to the method reported by Bao et al. (2013) [25] with three replicates. First, $100 \mathrm{~mL}$ of deionized water were added into a cup with a diameter of $45 \mathrm{~mm}$. The top of the cup was sealed with film and promptly weighted $\left(m_{1}\right)$. Then, the cup was stored in the dryer of concentrated sulfuric acid, which was reserved under the temperature of $25{ }^{\circ} \mathrm{C}$ and the humidity of $90 \% \mathrm{RH}$. Finally, the water vapor permeability cup was taken out and weighed $\left(m_{2}\right)$ on the 26th day. Water vapor permeability of films was expressed in units of $\mathrm{mg} /\left(\mathrm{cm}^{2} \cdot 26 \mathrm{~d}\right)$ and calculated using the following equation: $\left(m_{1}-m_{2}\right) / A$, where $A$ is the test area of the films in $\mathrm{cm}^{2}$.

The glass-transition temperature $\left(T_{\mathrm{g}}\right)$ of the model membrane was assayed using differential scanning calorimetry (DSC, Pyris-DSC Perkin-Elmer, Wellesley, MA, USA). Approximately $10 \mathrm{mg}$ of isolated film were heated at a rate of $20{ }^{\circ} \mathrm{C} / \mathrm{min}$, and their thermal behaviors of the samples were examined under nitrogen between -100 and $150{ }^{\circ} \mathrm{C}$. The glass transition temperature $\left(T_{\mathrm{g}}\right)$ was measured at the onset of the corresponding heat capacity jump. Two successive scans were made for each sample and all calculations were performed on the second heating cycle.

Tensile properties of isolated films were measured using a universal testing machine (CMT 5254, Shenzhen SANS Testing Machine Co., Ltd., Shenzhen, China) according to the procedures outlined in ASTM D638-03 [26] with five replicates. A dumb-bell shaped die wide (type A2 with a length of $10 \mathrm{~mm}$ ) was cut from the isolated film and the measuring speed was $200 \mathrm{~mm} / \mathrm{min}$. Elongation at break was defined as the elongation ratio with respect to the initial gauge length when the film broke. Young's modulus was calculated from the first slope of the stress-strain curve using least-squares best fitting. Hardness tests (Shore A) were conducted on a hardness tester (XL-A, Jiangdu MingZhu Testing Machine Co., Ltd., Yangzhou, China), with reference to ASTM D2240-03 [27] at $23 \pm 2{ }^{\circ} \mathrm{C}$ and a relative humidity of $50 \%$. All hardness data were the average values of five runs.

Urea granules (400 g) were loaded into the Wurster fluidized bed (LDP-3, Changzhou Jiafa Granulation Drying Equipment Co., Ltd., Changzhou, China). After preheating at $45^{\circ} \mathrm{C}$ for $10 \mathrm{~min}$, the emulsion was sprayed uniformly to urea granules. The atomizing pressure of the atomizing nozzle was $0.1 \mathrm{MPa}$, and the spray rate was $2.5 \mathrm{~g} / \mathrm{min}$. The coated granules were dried at $60^{\circ} \mathrm{C}$ in an oven for $24 \mathrm{~h}$. Coated urea granules were surrounded by a polymer coating with a thickness of $\sim 100 \mu \mathrm{m}$, and the weight of $9.1 \mathrm{wt} . \%$ of the total weight of the coated urea granule. The thickness of the coating was determined by graduated optical microscope. The coating was peeled off from the coated granule carefully and divided into pieces of $1 \mathrm{~mm} \times 3 \mathrm{~mm}$. The coating thickness was determined by graduated optical microscope when the vertical sections of the pieces were faced onto the microscope objective. Five grams of coated urea granules $(M)$ were cut open with a blade. The coating was cleaned and dried at $60^{\circ} \mathrm{C}$ in an oven to a constant weight $(m)$. The coating content was calculated as $m \times 100 / \mathrm{M}$.

The nutrients release profiles were estimated as the cumulative dissolution versus time (days). Five $\mathrm{g}$ of coated urea were placed in a glass bottle containing $100 \mathrm{~mL}$ of deionized water and kept at $25{ }^{\circ} \mathrm{C}$ with three replicates. Urea solution was replaced with $100 \mathrm{~mL}$ of deionized water periodically $(1,3,5,7,10,14,28$, and 42 days). Urea content was evaluated by the para-dimethylaminobenzaldehyde colorimetric method (Epoch microplate spectrophotometer, Biotek, Winooski, VT, USA). On the 42nd day of release, the coated urea was grounded to determine the content of residual nutrient. 


\section{Results}

\subsection{Nutrient Release Behavior of Coated CRU}

The controlled release performance is precondition for evaluating whether the coatings are suitable for CRU. The nutrient release profile of CRU is illustrated in Figure 1, and the results of the preliminary solubility and release duration are summarized in Table 1. Incorporation of silica nanoparticles into polyacrylate emulsion resulted in a significantly delayed release from CRU compared with pure polyacrylate. Firstly, the preliminary solubility of CRU decreased from $38.3 \%$ to a range of $2.2 \%-9.1 \%$ with changing silica content from $0.5 \mathrm{wt}$ \% to $2.0 \mathrm{wt}$.\%. The low preliminary solubility of CRU could prevent seedling burning if CRU and conventional urea were blended in a one-off application as basal fertilizer [6]. Secondly, the nutrient release durations were extended from 8 to 27-33 days so that the unsynchronized relationships between the crop's requirement and the nutrient release of the polymer emulsion coated CRU could be resolved [28]. Thirdly, nutrient release profiles were changed from an "inverted-L" pattern (the nutrient release rapidly in the beginning and then leveled off) to a " $\mathrm{S}$ " pattern (the nutrient released little during the lag period, at a constant rate during the linear period, decreasing gradually during the decaying period). The " $\mathrm{S}$ " pattern synchronized better with nutrient uptake by plants than the "inverted-L" pattern [2]. Thus, CRU coated with polyacrylate/silica nanoparticles hybrid emulsions has a great potential in increasing the fertilizer utilization efficiency significantly and reducing the ecological environment pollution [29].

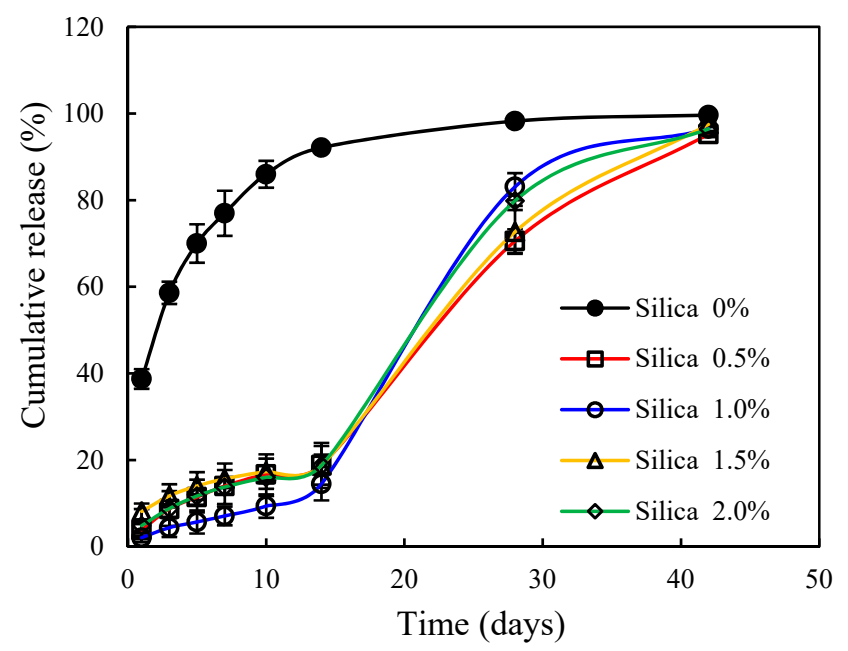

Figure 1. Nutrient cumulative release profiles of controlled release urea coated with polyacrylate emulsion (silica $0 \mathrm{wt.} \%$ ) and hybrid emulsions with 0.5 wt. $\%, 1.0 \mathrm{wt} \%$, 1.5 wt. $\%$, and 2.0 wt. $\%$ silica spheres.

Table 1. Preliminary solubility and release duration of controlled-release urea (CRU).

\begin{tabular}{ccc}
\hline Silica Content (wt.\%) & Preliminary Solubility (\%) & Release Duration (days) \\
\hline 0 & $38.3 \mathrm{a}$ & $8 \mathrm{C}$ \\
0.5 & $4.3 \mathrm{~b}$ & $33 \mathrm{~A}$ \\
1.0 & $2.2 \mathrm{~b}$ & $27 \mathrm{~B}$ \\
1.5 & $5.4 \mathrm{~b}$ & $32 \mathrm{~A}$ \\
2.0 & $9.1 \mathrm{~b}$ & $28 \mathrm{~B}$
\end{tabular}

Means with the same letter (small letters for preliminary solubility and capital letters for release duration) are not significantly different at $p \leq 0.05$ level.

\subsection{Fourier-Transform Infrared Photoacoustic Spectrum}

The results of the fourier-transform infrared photoacoustic spectrum (FTIR-PAS) analysis of pure polyacrylate film and its hybrid films are shown in Figure 2. The peak at $1726 \mathrm{~cm}^{-1}$ is the 
stretching vibration of ester bonds [30], the intensity of which increased with the increment of silica content from $0.5 \mathrm{wt} . \%$ to $2.0 \mathrm{wt} . \%$. It clearly confirmed that the crosslinking reaction occurred between the carboxyl from polyacrylate and the hydroxyl from silica nanoparticles (Scheme 1). The reaction took place under acidic conditions, and the acidity of polyacrylate emulsion provided a good condition for the crosslinking reaction because the $\mathrm{pH}$ of the polyacrylate emulsion was about 3.5. Kim et al. (2004) also reported that the hydroxyl of the polyvinyl alcohol (PVA) reacted with silica when they prepared $\mathrm{PVA} / \mathrm{SiO}_{2}$ hybrid membranes [30]. In addition, the hybrid films showed that the enhancement in hydrogen bonding at around $2900-3000 \mathrm{~cm}^{-1}$ compared to the pure polyacrylate. The un-reacted hydroxyl in the silica nanoparticles formed hydrogen bonds with the ether groups of the polyacrylate [31].

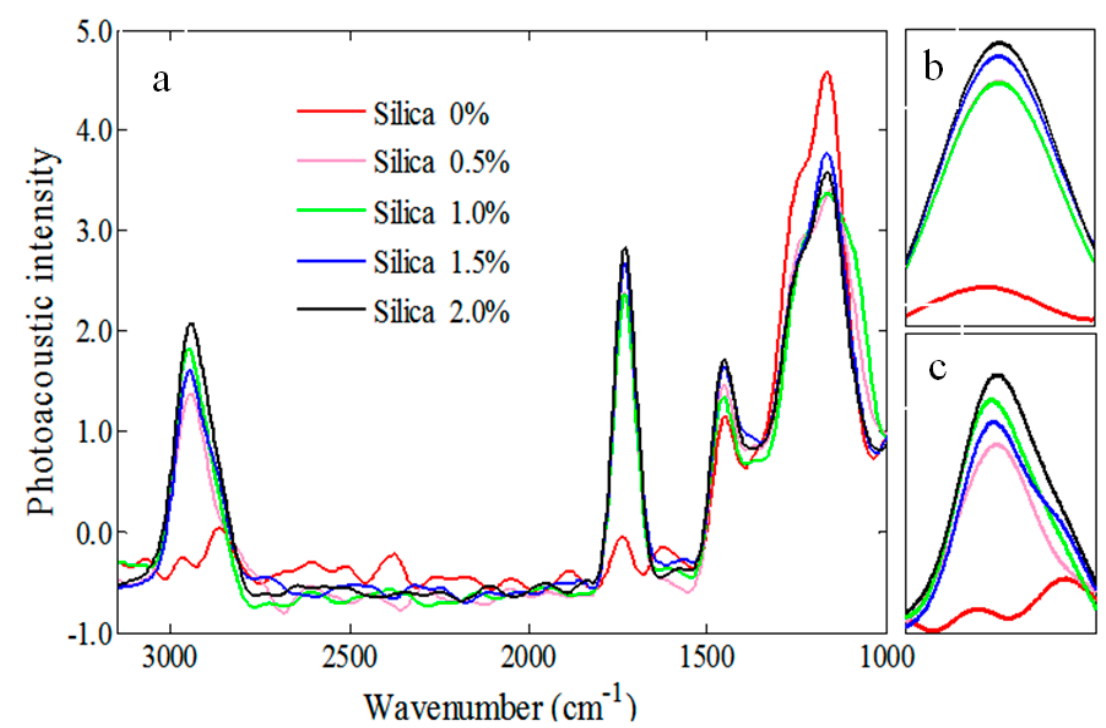

Figure 2. FTIR spectra (a) of the pure polyacrylate film (silica 0 wt.\%) and hybrid films with 0.5 wt.\%, $1.0 \mathrm{wt} . \%, 1.5 \mathrm{wt} . \%$, and $2.0 \mathrm{wt} . \%$ silica. The subintervals of the spectra $1650-1800 \mathrm{~cm}^{-1}$ (b) and $2800-3060 \mathrm{~cm}^{-1}$ (c) were also put beside for clarity.

Silica nanoparticle

Polyacrylate

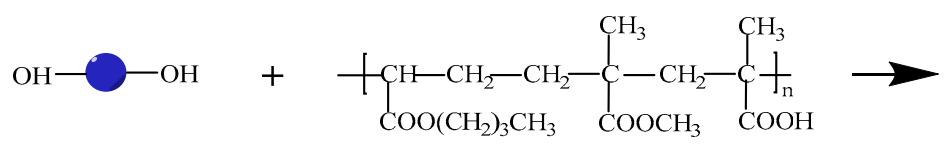

Reaction between silica nanopartile and polyacrylate

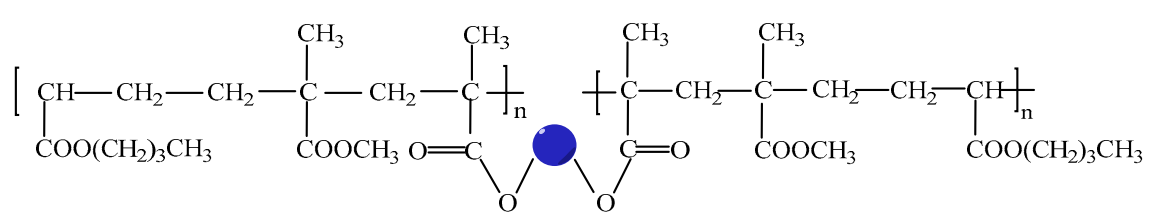

Scheme 1. The reaction between the hydroxyl groups in the surface of silica nanoparticles and the carboxyl group of polyacrylate.

\subsection{Water Absorption Rate}

The water resistance of the films was characterized by water absorption rate, as shown in Figure 3. The water absorption rate of the films decreased with an increase in silica content. Hydroxyl existed on the surface of silica nanoparticles [24], which reacted with the carboxylic groups of polyacrylate [15]. Thus, silica nanoparticles served as a crosslinking site, and the three-dimensional crosslinking network 
was formed in the hybrid films. As the aqueous silica nanoparticles were distributed in the polyacrylate emulsion evenly, the crosslinking densities of the nanoparticle films increased along with increasing silica content, which was considered to enhance the water resistance of hybrid films [24].

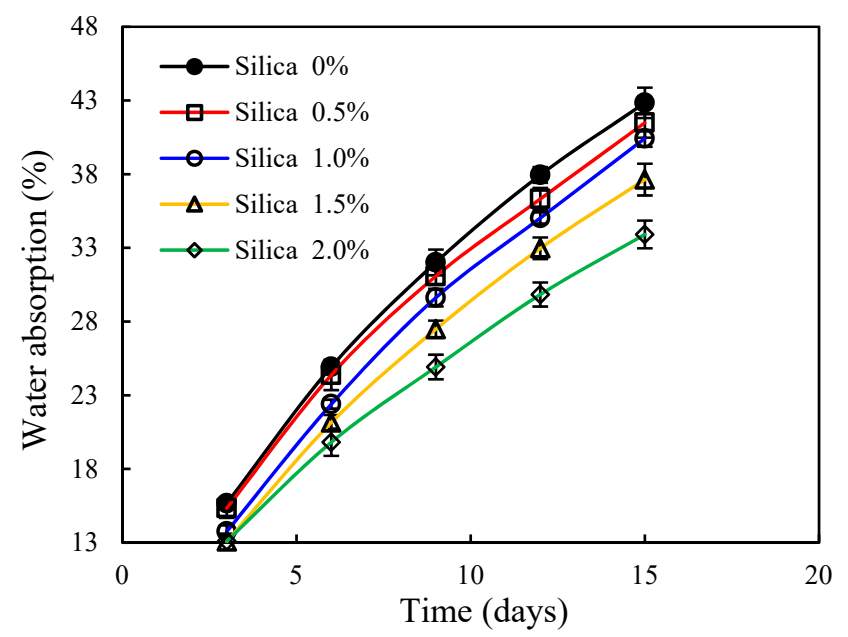

Figure 3. Water absorption of pure polyacrylate film (silica $0 \mathrm{wt} . \%$ ) and hybrid films with $0.5 \mathrm{wt}$. $\%$, 1.0 wt. $\%, 1.5$ wt. $\%$, and 2.0 wt. $\%$ silica.

The absorbed water could be divided into free water and bound water. Figure 3 shows that the absorbed water content decreased with silica content up to $2.0 \mathrm{wt}$.\%. However, Kim reported that the bound water ratios of the hybrid films increased with silica content because more water molecules were hydrogen-bonded with the Si-OH [25]. Therefore, the free water content of films reduced with silica content. According to vehicle mechanism, the free water could act as a nutrient-carrying medium [32]. Thus, we expected that the hybrid films containing high silica content would be more effective for nutrient barrier.

\subsection{Water Vapor Permeability}

The water vapor permeability through hybrid films was illustrated as a function of silica content, as in Figure 4. Hybrid films prepared with silica nanoparticles were found to be significantly less permeable to water vapor than the pure polyacrylate film. The water vapor permeability through the hybrid films decreased up to $1.0 \mathrm{wt} . \%$ silica content, and they increased above $1.0 \mathrm{wt} . \%$ silica content. Silica nanoparticles reduced the water vapor molecular permeation rate because the nonpermeable silica nanoparticles acted as a barrier in the hybrid films, and the crosslinking reaction decreased the polyacrylate mobility [31]. Moreover, the large surface area of silica nanoparticles enhanced the tortuosity of the polyacrylate pathway [22]. When the silica content was further increased to $1.5 \mathrm{wt} . \%$ and $2.0 \mathrm{wt} . \%$, the hybrid films became more permeable to water vapor due to the formation of nanoparticle aggregations. The aggregated silica nanoparticles decreased their effective surface area [33] and the compactness of the polyacrylate chains [31], which in turn gave rise to the feasibility of penetration through the hybrid films containing high silica contents [34]. A similar result was reported by Cristea, who found that the hybrid film prepared with $1 \mathrm{wt} . \% \mathrm{ZnO}$ nanoparticles was found to be less permeable to water vapor than the pure polyacrylate film and the hybrid film containing $2 \mathrm{wt} . \%$ $\mathrm{ZnO}$ nanoparticles [33]. 


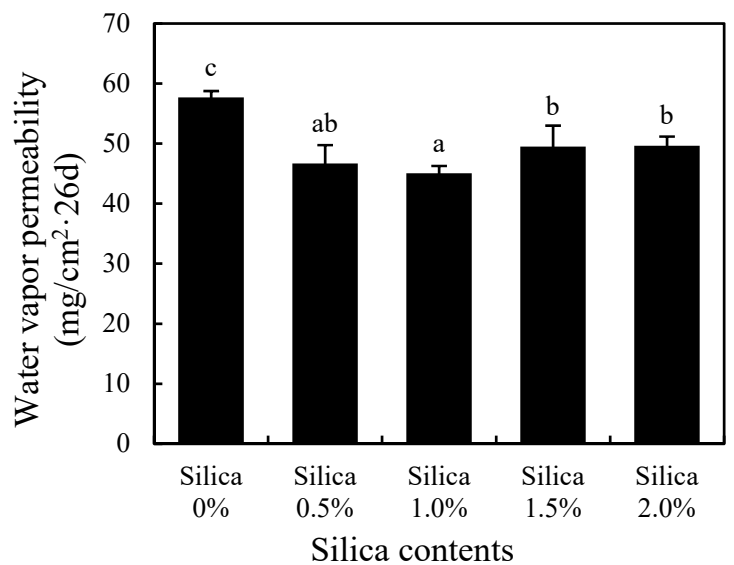

Figure 4. Water vapor permeability of pure polyacrylate film (silica $0 \mathrm{wt}$. $\%$ ) and hybrid films with 0.5 wt. $\%, 1.0$ wt. $\%, 1.5$ wt. $\%$, and 2.0 wt. $\%$ silica.

The trend of the water vapor permeability of the hybrid films was inconsistent with the water absorption behavior. Silica nanoparticles dispersed more uniformly in the polyacrylate matrix for determining water absorption rate than that for determining water vapor permeability. The thickness of the films for determining the water vapor permeability $(0.85 \mathrm{~mm})$ was almost three times higher than that of the films for determining the water absorption rate $(0.3 \mathrm{~mm})$. The aggregation did not have enough time to form before the film formation when the thin films were prepared for determining the water absorption rate. Thus, with a continued increase in the silica nanoparticle content to $1.5 \mathrm{wt} . \%$ and $2.0 \mathrm{wt} . \%$, the crosslinking densities of the hybrid films continued to increase for determining water absorption rate, while nanoparticles aggregates formed in the hybrid films for determining water vapor permeability.

\subsection{Glass Transition Temperature of Films}

The glass-transition temperature, which closely related to film-formation states of the CRU coating, was also used to select the coatings of CRU. As shown in Table 2, the glass-transition temperature of pure polyacrylate was $6.38{ }^{\circ} \mathrm{C}$. It would result in a sticky coating and poor processability of CRU. During the coating process, coated granules adhered to each other, and the coating integrity was damaged. After the addition of $0.5 \mathrm{wt} . \%$ and $1.0 \mathrm{wt} . \%$ silica nanoparticles, the glass transition temperature of the hybrid films was increased to 9.54 and $9.97^{\circ} \mathrm{C}$, respectively. This increase was attributed to the restricted mobility of the polyacrylate chains by the crosslinking reaction and the hydrogen bonds between polyacrylate chains and silica nanoparticles [15]. Pishvaei and Tabrizi reported that the incorporation of silica nanoparticles can increase the glass-transition temperature of hybrid films [35]. The increase of $T_{\mathrm{g}}$ was beneficial to improving the processability of CRU coated with hybrid emulsions. However, as the content of silica nanoparticles continued to increase to $1.5 \mathrm{wt} . \%$ and $2.0 \mathrm{wt} . \%, T_{\mathrm{g}}$ was progressively decreased to 8.50 and $6.23{ }^{\circ} \mathrm{C}$, respectively. Although pre-dispersed nanoparticles in aqueous systems displayed a more efficient dispersion than powder nanoparticles, the free volume appeared at the polyacrylate-nanoparticle interface due to the formation of nanoparticle aggregations at high silica contents, which were probably responsible for the $T_{\mathrm{g}}$ decrease $[32,33,36,37]$. 
Table 2. Glass-transition temperatures and mechanical properties of films.

\begin{tabular}{cccccc}
\hline $\begin{array}{c}\text { Silica Content } \\
\text { (wt.\%) }\end{array}$ & $\begin{array}{c}\boldsymbol{T}_{\mathbf{g}} \\
\left({ }^{\circ} \mathbf{C}\right)\end{array}$ & $\begin{array}{c}\text { Hardness } \\
\text { (Share A) }\end{array}$ & $\begin{array}{c}\text { Tensile Stress } \\
\text { at Break (MPa) }\end{array}$ & $\begin{array}{c}\text { Elongation at } \\
\text { Break (\%) }\end{array}$ & $\begin{array}{c}\text { Young's Modulus } \\
(\mathbf{M P a})\end{array}$ \\
\hline 0 & 6.38 & $34 \mathrm{~b}$ & $3.47 \mathrm{~b}$ & $1033.54 \mathrm{a}$ & $29.42 \mathrm{~b}$ \\
0.5 & 9.54 & $38 \mathrm{a}$ & $3.78 \mathrm{ab}$ & $1181.62 \mathrm{a}$ & $32.40 \mathrm{ab}$ \\
1.0 & 9.97 & $38 \mathrm{a}$ & $4.66 \mathrm{a}$ & $1013.23 \mathrm{a}$ & $36.00 \mathrm{a}$ \\
1.5 & 8.50 & $38 \mathrm{a}$ & $3.00 \mathrm{bc}$ & $887.66 \mathrm{a}$ & $24.04 \mathrm{c}$ \\
2.0 & 6.23 & $38 \mathrm{a}$ & $2.48 \mathrm{c}$ & $962.99 \mathrm{a}$ & $23.69 \mathrm{c}$ \\
\hline
\end{tabular}

Means with the same letter are not significantly different at $p \leq 0.05$ level.

\subsection{Mechanical Properties of Isolated Films}

It is necessary to develop coating materials that combine hardness, strength, and flexibility. Hardness is characterized by shore A hardness. The strength and flexibility of the films were characterized by tensile stress and elongation at break, respectively. Materials with high values of Young's modulus are associated with high strength but low flexibility. In Table 2, the mechanical properties of the films are summarized. The introduction of silica nanoparticles increased hardness from 34 to 38. The addition of silica nanoparticles with high hardness and Young's modulus enhanced the cohesive force in the polyacrylate matrix to prevent sharp objects from indentation or from polyacrylate chains tearing [38]. Mizutai et al. reported a similar trend for the pencil hardness of hybrids and pure samples [39]. In comparison with the pure polyacrylate film, it was obvious that the incorporation of $0.5 \mathrm{wt} . \%$ and $1.0 \mathrm{wt} . \%$ silica nanoparticles improved the tensile strength and modulus due to the crosslinking reaction and hydrogen bonds between polyacrylate chains and silica nanoparticles; however, when the content of silica nanoparticles increased to $1.5 \mathrm{wt} . \%$ and $2.0 \mathrm{wt} . \%$, tensile strength and Young's modulus decreased. A degree of nanoparticle dispersibility in polyacrylate matrix was crucial to the tensile strength and modulus [40,41]. The hybrid films containing $1.5 \mathrm{wt} . \%$ and $2.0 \mathrm{wt} . \%$ silica nanoparticles displayed significant aggregation, which led to incomplete load transfer and finally exhibited lower strength and modulus compared to hybrid films with more uniform particle dispersion [42,43]. The change of mechanical property correlated to the variation of $T_{\mathrm{g}}$ of the hybrid films.

\section{Discussion}

The controlled-release performance of the CRU was inevitably relevant to the properties of the coating, i.e., water vapor permeability, water-resistance performance, glass-transition temperature, hardness, stress, and Young's modulus. Bivariate correlation analysis was used to analyze the relationship of all these properties of the coating with the preliminary solubility and the release duration of CRU, respectively (Table 3). Preliminary solubility of CRU is strongly related to the hardness, water vapor permeability, and $T_{\mathrm{g}}$ of the coatings. The addition of $1.0 \mathrm{wt} . \%$ silica nanoparticles increased hardness and $T_{\mathrm{g}}$ and decreased water vapor permeability of the hybrid films. In general, an increase in hardness promotes the high wear-resistance of hybrid films and maintains the thickness of the coating during preparation, transportation, and application [37]. The thickness of the coating was proven to have a great influence on the nutrient release rate of CRU [29]. Furthermore, $T_{\mathrm{g}}$ of the hybrid films containing $1.0 \mathrm{wt} . \%$ silica nanoparticles increased from 6.38 to $9.97^{\circ} \mathrm{C}$. This improved the processability of CRU and led to less breakage of CRU granules as a result of the adhesion of the urea granules during preparation and storage. Reduction of water vapor permeability slowed both water diffusion into the core and urea diffusion outside the core. Thus, preliminary solubility was reduced significantly. Release duration is closely correlated with the hardness and water vapor permeability of the coatings. This indicates that $T_{\mathrm{g}}$ mainly affects the preliminary solubility of CRU but has no significant influence on the release duration of CRU. Meanwhile, preliminary solubility is significantly related to the release duration of CRU with Pearson correlation coefficients of -0.925 . This suggests the extension of the release duration is mainly caused by the reduction of the preliminary solubility. 
Table 3. Pearson correlation coefficients between the properties of coatings and the controlled-release parameters of CRU.

\begin{tabular}{|c|c|c|c|c|c|c|}
\hline Release Parameters & $\begin{array}{c}\text { Water } \\
\text { Uptake (\%) }\end{array}$ & $\begin{array}{l}\text { Water Vapor } \\
\text { Permeability } \\
\left(\mathrm{mg} / \mathrm{cm}^{2} \cdot 26 \mathrm{~d}\right)\end{array}$ & $T_{\mathrm{g}}\left({ }^{\circ} \mathrm{C}\right)$ & $\begin{array}{l}\text { Hardness } \\
\text { (Share A) }\end{array}$ & $\begin{array}{l}\text { Stress } \\
(\mathrm{MPa})\end{array}$ & $\begin{array}{c}\text { Modulus } \\
\text { (MPa) }\end{array}$ \\
\hline Preliminary solubility & 0.150 & $0.935^{* *}$ & $-0.668^{* *}$ & $-0.959 * *$ & -0.159 & -0.104 \\
\hline Release duration & -0.296 & $-0.863^{* *}$ & 0.473 & $0.965^{* *}$ & 0.088 & -0.066 \\
\hline
\end{tabular}

The properties of hybrid films evidently varied when changing the content of silica nanoparticles from $0.5 \mathrm{wt} . \%$ to $2.0 \mathrm{wt} . \%$, while the controlled-release performance of CRU coated with hybrid emulsions containing different content of silica nanoparticles showed less variation. During the $1.5 \mathrm{~h}$ of the coating process, only $0.75 \mathrm{wt} . \%$ silica nanoparticles could be held in the polyacrylate emulsion, and the remainder formed a precipitate because agglomeration affected the stability of the hybrid emulsion. The actual content of silica nanoparticles in the hybrid coatings was no more than $0.75 \mathrm{wt} . \%$, regardless of the loading of the silica nanoparticles. Although the four loadings of silica nanoparticles in the experimental design were $0.5 \%, 1.0 \%, 1.5 \%$, and $2.0 \%$, there were only two contents of silica nanoparticles in the coatings, $0.5 \%$ and $0.75 \%$. It was found that the properties of the hybrid films containing $0.5 \%$ and $1.0 \%$ silica nanoparticles did not differ significantly. Therefore, it could be explained why the nutrient cumulative release profiles of the controlled release urea prepared with hybrid emulsions containing four different amounts of silica nanoparticles were so similar. The enhancement of physicochemical properties and the final barrier effectiveness of nanoparticles was dependent on the dispersion degree of the nanoparticles and the interfacial interaction strength $[20,33]$. Further research is required to obtain strong interfacial interactions between silica nanoparticles and polymer and well-dispersed silica nanoparticles in the polymer emulsion. For instance, a silane coupling agent could be used to strengthen the interfacial interactions between silica nanoparticles and polymer. Moreover, an ultrasonic oscillation method could be adopted to reduce the formation of agglomerations during the process of coating. The content of silica nanoparticles in the coating should be increased from the current $0.75 \mathrm{wt} . \%$ to $1.0 \mathrm{wt} . \%$, but there is no need to continue to increase to $1.5 \mathrm{wt} . \%$. The incorporation of $1.0 \mathrm{wt} . \%$ silica nanoparticles improved mechanical strength, processability, and controlled release performance; however, when the content of silica nanoparticles increased to $1.5 \mathrm{wt} . \%$ and $2.0 \mathrm{wt} . \%$, these properties started to decrease.

\section{Conclusions}

Aqueous silica nanoparticles were found to be highly effective in delaying urea release from CRU coated with polyacrylate/silica hybrid emulsions. After incorporating $1.0 \mathrm{wt} . \%$ silica nanoparticles into a polyacrylate emulsion, the preliminary solubility of CRU was decreased from $38.3 \mathrm{wt} . \%$ to $2.2 \mathrm{wt} . \%$, and the release durations were extended from 8 to 27 days. The extension of the release duration was mainly caused by the reduction of the preliminary solubility when polyacrylate/silica hybrid emulsions were applied as coatings for the controlled-release urea. The addition of $1.0 \mathrm{wt} . \%$ aqueous silica nanoparticles dramatically increased hardness, tensile stress, and the glass-transition temperature, and decreased water vapor permeability and water absorption rate. The delayed release of urea upon the addition of silica nanoparticles was attributable to: (1) the high wear-resistance of hybrid films due to increased hardness; (2) the formation of the tortuous diffusion pathway for water vapor and urea molecules; (3) less breakage of CRU granules because of improved processability. Although aqueous silica nanoparticles displayed a more efficient dispersion in the polymer emulsion than the powder nanoparticles, the aggregations of silica nanoparticles occurred when the content of silica nanoparticles was high (1.5-2.0 wt.\%). Thus, further attempts should be made to achieve the uniform dispersal of silica nanoparticles in polymer emulsion at high contents so that the urea release could be further retarded. Overall, the simple blending of aqueous silica nanoparticles with 
polyacrylate emulsion produced an outstanding coating for delaying urea release. This work views broad application prospect in waterborne polymer coated controlled-release fertilizers.

Author Contributions: Conceptualization, C.D. and J.Z.; Methodology, Y.S.; Investigation, Y.S.; Data Curation, Y.S.; Writing-Original Draft Preparation, Y.S.; Writing-Review and Editing, C.D.; Supervision, C.D. and J.Z.; Project Administration, J.Z.; Funding Acquisition, C.D. and J.Z.

Funding: This work was funded by the National Key Research and Development Program of China (2017YFD0200704), the Key Research and Development Program of Jiangsu province (BE2017388), the 13th Five Year Plan Forefront Project of Institute of Soil Science, Chinese Academy of Sciences (ISSASIP1646) and the "STS" Project from Chinese Academy of Sciences (KFJ-PTXM-003, KFJ-STS-QYZX-047).

Acknowledgments: The authors would like to express their thanks to the responsible editors and anonymous reviewers for their corrections and suggestions to the manuscript.

Conflicts of Interest: The authors declare no conflict of interest.

\section{References}

1. Premarathna, L.; Mclaughlin, M.J.; Kirby, J.K.; Hettiarachchi, G.M.; Stacey, S.; Chittleborough, D.J. Selenate-enriched urea granules are a highly effective fertilizer for selenium biofortification of paddy rice grain. J. Agric. Food Chem. 2012, 60, 6037-6044. [CrossRef] [PubMed]

2. Shaviv, A.; Mikkelsen, R.L. Controlled-release fertilizers to increase efficiency of nutrient use and minimize environmental degradation-A review. Fertil. Res. 1993, 35, 1-12. [CrossRef]

3. Smith, L.E.D.; Siciliano, G. A comprehensive review of constraints to improved management of fertilizers in China and mitigation of diffuse water pollution from agriculture. Agric. Ecosyst. Environ. 2015, 209, 15-25. [CrossRef]

4. Costa, M.M.E.; Cabralalbuquerque, E.C.M.; Alves, T.L.M.; Pinto, J.C.; Fialho, R.L. Use of polyhydroxybutyrate and ethyl cellulose for coating of urea granules. J. Agric. Food Chem. 2013, 61, 9984-9991. [CrossRef] [PubMed]

5. Azeem, B.; Kushaari, K.; Man, Z.B.; Basit, A.; Thanh, T.H. Review on materials \& methods to produce controlled release coated urea fertilizer. J. Control. Release 2014, 181, 11-21. [CrossRef] [PubMed]

6. Yang, Y.; Zhang, M.; Li, Y.; Fan, X.; Geng, Y. Controlled-release urea commingled with rice seeds reduced emission of ammonia and nitrous oxide in rice paddy soil. J. Environ. Qual. 2013, 42, 1661-1673. [CrossRef] [PubMed]

7. Donida, M.W.; Rocha, S.C.S. Coating of urea with an aueous polymeric suspension in a two-dimensional spouted bed. Dry. Technol. 2002, 20, 685-704. [CrossRef]

8. Shen, Y.; Du, C.; Zhou, J. Aqueous polyacrylate/poly(silicone-co-acrylate) emulsion coated fertilizers for slow nutrient-release application. J. Appl. Polym. Sci. 2014, 131, 469-474. [CrossRef]

9. Zhou, Z.; Du, C.; Li, T.; Shen, Y.; Zeng, Y.; Du, J.; Zhou, J. Biodegradation of a biochar-modified waterborne polyacrylate membrane coating for controlled-release fertilizer and its effects on soil bacterial community profiles. Environ. Sci. Pollut. Res. Int. 2015, 22, 8672-8682. [CrossRef] [PubMed]

10. Zhao, C.; Shen, Y.; Du, C.; Zhou, J.; Wang, H.; Chen, X. Evaluation of waterborne coating for controlled-release fertilizer using wurster fluidized bed. Ind. Eng. Chem. Res. 2010, 49, 9644-9647. [CrossRef]

11. Shen, Y.; Du, C.; Zhou, J.; Ma, F. Application of nano Fe $\mathrm{F}^{\mathrm{III}}$-tannic acid complexes in modifying aqueous acrylic latex for controlled-release coated urea. J. Agric. Food Chem. 2017, 65, 1030-1036. [CrossRef] [PubMed]

12. Yuan, W.; Shen, Y.; Ma, F.; Du, C. Application of graphene-oxide-modified polyacrylate polymer for controlled-release coated urea. Coatings 2018, 8, 64. [CrossRef]

13. An, D.; Liu, B.; Yang, L.; Wang, T.J.; Kan, C. Fabrication of graphene oxide/polymer latex composite film coated on $\mathrm{KNO}_{3}$ fertilizer to extend its release duration. Chem. Eng. J. 2017, 311, 318-325. [CrossRef]

14. Du, X.; He, J. A Self-templated etching route to surface-rough silica nanoparticles for superhydrophobic coatings. ACS Appl. Mater. Interface 2011, 3, 1269-1276. [CrossRef]

15. Ma, J.Z.; Hu, J.; Zhang, Z.J. Polyacrylate/silica nanocomposite materials prepared by sol-gel process. Eur. Polym. J. 2007, 43, 4169-4177. [CrossRef]

16. Liu, J.L.; Ma, J.Z.; Bao, Y.; Zhu, Z.F.; Liu, Y.H.; Zheng, Y. Preparation of polyacrylate/ZnO nanocomposite. Mater. Sci. Forum 2011, 694, 430-434. [CrossRef]

17. Sheibatothman, N.; Bourgeatlami, E. Use of silica particles for the formation of organic-inorganic particles by surfactant-free emulsion polymerization. Langmuir 2009, 25, 10121-10133. [CrossRef] 
18. Chau, J.L.H.; Hsieh, C.C.; Lin, Y.M.; Li, A.K. Preparation of transparent silica-PMMA nanocomposite hard coatings. Prog. Org. Coat. 2008, 62, 436-439. [CrossRef]

19. An, Q.; Wei, X.; Hao, L.; Fu, Y.; Huang, L. Fabrication of superhydrophobic fabric coating using microphase-separated dodecafluoroheptyl-containing polyacrylate and nanosilica. J. Appl. Polym. Sci. 2013, 128, 3050-3056. [CrossRef]

20. Schmidt, D.F.; Giannelis, E.P. Silicate dispersion and mechanical reinforcement in polysiloxane/layered silicate nanocomposites. Chem. Mater. 2010, 22, 167-174. [CrossRef]

21. Li, L.; Sun, Y.; Cao, B.; Song, H.; Xiao, Q.; Yi, W. Preparation and performance of polyurethane/mesoporous silica composites for coated urea. Mater. Des. 2016, 99, 21-25. [CrossRef]

22. Huang, Y.; Hu, M.; Yi, S.; Liu, X.; Li, H.; Huang, C.; Luo, Y.; Li, Y. Preparation and characterization of silica/fluorinated acrylate copolymers hybrid films and the investigation of their icephobicity. Thin Solid Films 2012, 520, 5644-5651. [CrossRef]

23. Choudalakis, G.; Gotsis, A.D. Free volume and mass transport in polymer nanocomposites. Curr. Opin. Colloid Interface Sci. 2012, 17, 132-140. [CrossRef]

24. Zhou, J.; Xin, C.; Hao, D.; Ma, J.; Ma, Y. Synthesis and characterization of nano-SiO ${ }_{2}$ modified fluorine-containing polyacrylate emulsifier-free emulsion. Appl. Surf. Sci. 2015, 331, 504-511. [CrossRef]

25. Bao, Y.; Yang, Y.; Ma, J. Fabrication of monodisperse hollow silica spheres and effect on water vapor permeability of polyacrylate membrane. J. Colloid Interface Sci. 2013, 407, 155-163. [CrossRef] [PubMed]

26. ASTM D638-03 Standard Test Method for Tensile Properties of Plastics; ASTM International: West Conshohocken, PA, USA, 2003.

27. ASTM D2240-03 Standard Test Method for Rubber Property-Durometer Hardness; ASTM International: West Conshohocken, PA, USA, 2003.

28. Yang, Y.C.; Zhang, M.; Li, Y.; Fan, X.H.; Geng, Y.Q. Improving the quality of polymer-coated urea with recycled plastic, proper additives, and large tablets. J. Agric. Food Chem. 2012, 60, 11229-11237. [CrossRef]

29. Shaviv, A.; Raban, S.; Zaidel, E. Modeling controlled nutrient release from polymer coated fertilizers: Diffusion release from single granules. Environ. Sci. Technol. 2003, 37, 2251-2256. [CrossRef] [PubMed]

30. Kim, D.S.; Park, H.B.; Rhim, J.W.; Lee, Y.M. Preparation and characterization of crosslinked $\mathrm{PVA} / \mathrm{SiO}_{2}$ hybrid membranes containing sulfonic acid groups for direct methanol fuel cell applications. J. Membr. Sci. 2004, 240, 37-48. [CrossRef]

31. Torabi, B.; Ameri, E. Methyl acetate production by coupled esterification-reaction process using synthesized cross-linked PVA/silica nanocomposite membranes. Chem. Eng. J. 2016, 288, 461-472. [CrossRef]

32. Bryan, S.; Pivovar, B.S.; Wang, Y.; Cussler, E.L. Pervaporation membranes in direct methanol fuel cells. J. Membr. Sci. 1999, 154, 155-162. [CrossRef]

33. Cristea, M.V.; Riedl, B.; Blanchet, P. Effect of addition of nanosized UV absorbers on the physico-mechanical and thermal properties of an exterior waterborne stain for wood. Prog. Org. Coat. 2011, 72, 755-762. [CrossRef]

34. Wel, G.K.V.D.; Adan, O.C.G. Moisture in organic coatings-A review. Prog. Org. Coat. 1999, 37, 1-14. [CrossRef]

35. Pishvaei, M.; Tabrizi, F.F. Synthesis of high solid content polyacrylate/nanosilica latexes via miniemulsion polymerization. Iran. Polym. J. 2010, 19, 707-716.

36. Rittigstein, P.; Torkelson, J.M. Polymer-nanoparticle interfacial interactions in polymer nanocomposites: Confinement effects on glass transition temperature and suppression of physical aging. J. Polym. Sci. Polym. Phys. 2010, 44, 2935-2943. [CrossRef]

37. Pluta, M.; Jeszka, J.K.; Boiteux, G. Polylactide/montmorillonite nanocomposites: Structure, dielectric, viscoelastic and thermal properties. Eur. Polym. J. 2007, 43, 2819-2835. [CrossRef]

38. Zhou, C.; Xu, S.; Pi, P.; Cheng, J.; Wang, L.; Yang, J.; Wen, X. Polyacrylate/silica nanoparticles hybrid emulsion coating with high silica content for high hardness and dry-wear-resistant. Prog. Org. Coat. 2018, 121, 30-37. [CrossRef]

39. Mizutani, T.; Arai, K.; Miyamoto, M.; Kimura, Y. Preparation of spherical nanocomposites consisting of silica core and polyacrylate shell by emulsion polymerization. J. Appl. Polym. Sci. 2006, 99, 659-669. [CrossRef]

40. Guyard, A.; Persello, J.; Boisvert, J.P.; Cabane, B. Relationship between the polymer/silica interaction and properties of silica composite materials. J. Polym. Sci. Polym. Phys. 2010, 44, 1134-1146. [CrossRef] 
41. Bhattacharya, M.; Chaudhry, S. High-performance silica nanoparticle reinforced poly (vinyl alcohol) as templates for bioactive nanocomposites. Mater. Sci. Eng. C Mater. 2013, 33, 2601-2610. [CrossRef] [PubMed]

42. Khoonsap, S.; Supanchaiyamat, N.; Hunt, A.J.; Klinsrisuk, S.; Amnuaypanich, S. Improving water selectivity of poly(vinyl alcohol) (PVA)-Fumed silica (FS) nanocomposite membranes by grafting of poly (2-hydroxyethyl methacrylate) (PHEMA) on fumed silica particles. Chem. Eng. Sci. 2015, 122, 373-383. [CrossRef]

43. Li, J.; Suo, J.; Deng, R. Structure, Mechanical, and swelling behaviors of poly(vinyl alcohol) $/ \mathrm{SiO}_{2} \mathrm{hybrid}$ membranes. J. Reinf. Plast. Comp. 2010, 29, 618-629. [CrossRef]

(C) 2019 by the authors. Licensee MDPI, Basel, Switzerland. This article is an open access article distributed under the terms and conditions of the Creative Commons Attribution (CC BY) license (http:/ / creativecommons.org/licenses/by/4.0/). 